\title{
Language Transfer in Learning Japanese and Interlanguage Development
}

\author{
Xuexin Liu \\ Spelman College, Atlanta, United States
}

\begin{abstract}
This paper explains language transfer in second/foreign language learning by exploring the nature and sources of learner errors from some psycholinguistic perspectives. It claims that language transfer occurs at several abstract levels during second/foreign language production processes, rather than at the surface level of configurations. Three such abstract levels are identified in relation to potential sources of learner errors: the conceptual level, the functional level, and the positional level. Each level plays its own distinctive role, and the three levels are related in a sequential order of speech production process. It is assumed that language transfer may occur at any abstract level in second/foreign language production. Thus, language transfer and learner errors are viewed as part of learners' active mental process, rather than mere surface carryover of linguistic items from one language into another. For the study, the language transfer data, including both speaking and writing instances, were collected from adult learners of Japanese as a foreign language with English as their native language.
\end{abstract}

Keywords: language transfer, learner error, lexical-conceptual, predicate-argument, morphological realization

\section{Introduction}

In most theories of second language acquisition (SLA), the role of learners' first language (L1) in SLA has been narrowly focused to the effect of L1 influence on learners' second language developing system: interlanguage (IL) (Corder, 1967, 1981; Bailey, Madden, \& Krashen, 1974; Arabski, 1979; Ellis, 1982, 1985, among others). One weakness of this is that the notion of language transfer, though sometimes defined as a process in IL development, usually implies its negative role in IL development, and the relationship between learners' L1 and the target language (TL) is largely ignored. Recent refinements of language transfer theory have paid close attention to cross-linguistic influence in second language learning. Researchers adopting universalist approaches have found reconciliatory solutions between the traditional behaviorist and the cognitive approaches. Kellerman and Sharwood Smith (1986), Færch and Kasper (1987), Ringbom (1987), Odlin (1989), Gass and Selinker (1992), and Gass (1996) have been among the most influential in the field. For example, in their revised position on language transfer, Gass and Selinker (1992) hold that it is not incompatible to regard SLA as being affected by two interrelated processes: first, learners' utilization of their L1 knowledge and other languages known to them (the view advocated by Lado (1957)) and second, learners' build-up of a body of knowledge in which they rest hypotheses formed on the basis of the available L2 data (the view advocated by Dulay, Burt, and Krashen (1982)).

Xuexin Liu, associate professor, Ph.D, Department of World Languages and Literature, Spelman College. 
The question has been raised that if learners build up and revise the interim system by gradually increasing the complexity of the IL system, what is the origin of IL? To explore this issue, this study poses and answers several questions: From the beginning, is the TL always the "target" in projecting the morphosyntactic frame? If the TL is not sufficiently "known" to be used to project the frame, when is there no frame at all? Is there evidence that there necessarily always is a frame, and that learners first fall back on an L1 frame and then in some incremental sense, moves toward a TL frame? How does the change to the TL frame begin? Can this beginning be detected and what are the steps toward achieving the TL frame?

The major assumption regarding the nature of IL as a developing linguistic system to be presented in this study is that learners' L1 can be the origin of the initial IL system and it is the existence of the L1 as the initial reference point that gives rise to a special transitional IL system. Such an origin of the initial IL system can be understood as the source of language transfer. This is because learners may rely on their prior experience in concept and language learning and may use transfer in tier learning and production of the TL. This is also because early stages of second language learning are more likely to lead to transfer as the TL data available to learners are not fully accessible to form hypotheses about the TL rules. Thus, at least in the initial stage of learning, learners' L1 may affect the IL in framing the grammar of the TL. The IL performance instances discussed in this study indicate that L1 strategies may invade learners' vocabulary acquisition and sentence planning and thus constrain IL production. Learners may depend on their L1 strategies in order to map surface forms onto functions in the TL.

Different from some previous studies of language transfer in second or foreign language learning which described surface configurations of L2 production, this study explains instances of language transfer by exploring the nature of sources of learner errors from some psycholinguistic perspectives. As assumed in this study, it is abstract and complex lexical structures in IL that become potential sources of language transfer. Accordingly, this study explores the nature and sources of learner errors by assuming that language transfer may occur at three abstract linguistic levels: at the conceptual level, where lexical-conceptual structure (i.e., lexical items and their meanings) is realized; at the functional level, where predicate-argument structure (i.e., verbs and their required complements) is constructed; and at the positional level, where morphological realization patterns (i.e., word orders and their sentential frames) is achieved (cf. Levelt, 1989; Wei, 2000a, 2002). Thus, each level plays its own distinctive role, and there three levels are related in a sequential order of speech production process. This study assumes that language transfer may occur at any level during second or foreign language production process. Thus, language transfer and learner errors are viewed as part of learners' active mental process, rather than mere surface carryover of linguistic items from one language into another (cf. Schachter, 1983).

For the current study, the most commonly occurring learner errors were collected from adult learners of Japanese as an L2 (as a broadly defined term covering any foreign language learning) with English as their L1 (Liu, 1999, 2001). The language transfer data include both speaking and writing instances. One of the major pedagogical implications from this study is that lexical-conceptual structure, predicate-argument structure, and morphological realization patters are language-specific, and they must be learned as such, and sufficient acquisition of the TL at each of these linguistic levels will reduce or eliminate potential transfer from the previously learned ones in learners' L1. Thus, IL development is incrementally driven by acquiring the TL abstract and complex lexical structure. 


\section{Complex Lexical Structure and Its Implications for IL Construction}

It has been recognized that lexemes have more abstract elements than surface lexical items themselves and such abstract elements are contained in complex lexical structure that lexemes have. Lexical structure is complex because it contains several levels, such as lexical-conceptual structure, predicate-argument structure, and morphological realization patters (cf. Talmy, 1985; Rappaport \& Levin, 1988; Pinker, 1989; Levelt, 1989; Jackendoff, 1990; Bock \& Levelt, 1994; Myers-Scotton \& Jake, 1995; Jake, 1998; Wei, 2002). It has also been recognized that lexical-conceptual structure maps onto predicate-argument structure. This is because the theta criterion requires the mapping of lexical-conceptual structure (i.e., thematic structure) onto predicate-argument structure (i.e., syntactic structure). In addition to the thematic structure, the lexical-conceptual structure of a particular lexeme contains its semantic and pragmatic features and pointers to other lexemes with which it occurs (cf. Levelt, 1989; Bock \& Levelt, 1994). In addition, morphological realization patterns (cf. "lexicalization patterns" discussed in Talmy (1985)) should be included in a formal consideration of lexical structure in that the predicate-argument structure of a particular lexical entry specifies that a thematic role is assigned or received, and it is the morphological realization patterns that encode the realization of a particular morpheme/word order (cf. the production model of Levelt (1989) and Bock \& Levelt (1994), the bilingual production model of Myers-Scotton \& Jake (1995), and the bilingual lemma activation model of Wei (2002)).

IL is always the learner language which shows the surface forms of the intended TL, but it also contains abstract lexical structures from both the L1 and the TL (Myers-Scotton, 1994; Jake, 1998; Wei, 2000a, 2000b). Such lexical structures are called “abstract” because they cannot be observed at any surface level of IL production but at a deep level of the mental lexicon. This deep level is abstract because lemmas are abstract entries in the mental lexicon which support the surface realization of actual lexemes. Lemmas contain phonological, semantic, syntactic, pragmatic, and morphological information in the mental lexicon (Levelt, 1989). Thus, the mental lexicon is defined as the speaker's internal representation of language specific knowledge about the surface forms. It is assumed that lemmas are language-specific in the bilingual mental lexicon, and language-specific lemmas are in contact in IL production (Jake, 1998; Wei, 2002).

IL is a developing linguistic system, and, like other linguistic systems, its abstract lexical structure contains several discrete but interacting subsystems: lexical-conceptual structure, predicate-argument structure, and morphological realization patterns (Myers-Scotton, 1994). Such an abstract lexical structure in IL has different sources (Wei, 2000a, 2000b).

Lexical structure is modular and can be split and recombined in novel, yet constrained ways in constructing the linguistic system underlying IL (Jake, 1998). L1 transfer in IL construction is understood in terms of lexical structure at abstract levels, which becomes necessary to fill "gaps" in the incompletely acquired TL lexical structure. This is because parts of the lexical structure from L1 lexical entries may influence the lexical structure of incompletely acquired TL lexical entries in the developing IL. In other words, each of the three levels of the abstract lexical structure of IL may contain elements from L1 and/or TL, resulting in a composite developing linguistic system.

The above assumptions identify the nature of lexical structure and its role in IL development. What becomes directly relevant to discussion of language transfer in SLA is the assumption that the mental lexicon has abstract entries (i.e., lemmas) which contain pieces of information about particular lexemes, and the bilingual mental lexicon contains language-specific lemmas in contact. Such an abstract lexical structure 
becomes complex in IL because it may have different sources, such as those from L1 and/or TL. As assumed, parts of the lexical structure of L1 lexical entries may influence that of the incompletely acquired TL lexical entries in SLA.

The most commonly occurring language transfer instances or learner errors examined in this study were collected from adult learners of Japanese with English as their native language (Liu, 1999, 2001). The language transfer data include both speaking and writing instances, and the analysis and categorization of language transfer are based on the sources of learner errors as identified at each of the speech production levels: conceptual level, functional level, and positional level.

\section{Language Transfer in Lexical-Conceptual Structure}

The first level of speech production is the conceptual level, where the speaker generates preverbal message by selecting specific semantic/pragmatic feature bundles for realizing his/her communicative intentions (Bierwisch \& Schreuder, 1992; De Bot \& Schreuder, 1993). It has been recognized that although the conceptual structure is not language-specific (Levelt, 1989; Bierwisch \& Schreuder, 1992), languages differ in the way they lexicalize the components of a given conceptual structure (Talmy, 1985; Levin \& Pinker, 1991). As assumed, the lexical-conceptual structure of an IL lexeme may contain semantic or pragmatic features from an L1 counterpart. This is because although the L2 lexicon contains only those L2 lexical items that the speaker has learned, some of these lexical items are not yet fully specified in terms of the language-specific lemmas they contain. Thus, such an incompletely acquired lexicon is called IL lexicon. When learners' knowledge of the TL lexical items is incomplete or when their TL lexical items are insufficient to express their intended meanings, they may turn to similar or equivalent lexemes in their L1 at a certain point in IL production. In other words, at the conceptual level, because different languages have different lexical-conceptual structures, lexicalization patterns for certain universal concepts may differ across languages, and learners may select certain lexical items from the TL based on their native lexicalization patterns to express their intended meanings. Consequently, though they produce the TL lexical items, the selection of such items is based on the lexical-conceptual structure of their native language about the issue of language-specific lemma activation. Transfer in lexical-conceptual structure results in inappropriate lexical choices (cf. Kroll \& De Groot, 1997; Wei, 2000a, 2002). The following are some typical instances of transfer in lexical-conceptual structure produced by learners.

(PART: particle, TOP: topic, NOM: nominative, POSS: possessive, OBJ: object)

Example (1) watashi wa mainichi jūniji ni hirugohan ga aru.

I PART/TOP everyday 12 o'clock at lunch PART/NOM have

'I have lunch at 12 o'clock every day.'

In Example (1), the speaker uses the English concept aru (have) for "have lunch" rather than the Japanese equivalent taberu (eat) for the same concept.

Example (2) haha wa shokuji no ato shokki o suru. mother PART/TOP meal PART/POSS after dish PART/OBJ do '(My) mother do the dishes after the meal.'

In Example (2), the speaker translates the English expression "do the dishes" into Japanese by using suru (do) rather than “arau: wash”.

Example (3) kare wa shiken o toru. 


\section{he PART/TOP test PART/OBJ take}

'He will take the test.'

In Example (3), the speaker uses the verb toru (take) rather than $u k e r u$ (receive) for the equivalent English expression "take the test".

Example (4) yoru anata ni denwa o ageru. evening you to phone PART/OBJ give

'(I) will give you a call in the evening.'

In Example (4), the speaker translates the concept into Japanese by using the verb ageru (give) rather than kakeru as required in Japanese.

Example (5) watashi wa tenisu o asobu.

$$
\begin{aligned}
& \text { I PART/TOP tennis PART/OBJ play } \\
& \text { 'I play tennis.' }
\end{aligned}
$$

In Example (5), the speaker uses the verb asobu (play) based on the English expression rather than suru (do) as used in combination with other nouns.

The above instances of L1 lexical-conceptual structure in IL production provide the evidence that in IL production, though learners use the TL lexical items, the selection of those items may be caused by their incomplete of the TL lexical-conceptual structure of particular lexemes. In other words, language-specific lemmas for the universal concepts based on learners' L1 may activate or retrieve the TL lexical items in an inappropriate manner, resulting in L1 transfer in lexical-conceptual structure (cf. Levin \& Pinker, 1991). Thus, "transfer" in lexical-conceptual structure should be understood in terms of cross-linguistic transfer at the conceptual level.

\section{Language Transfer in Predicate-Argument Structure}

The second level of speech production is the functional level, where the speaker's generated preverbal messages at the conceptual level are syntactically encoded (Levelt, 1989; Wei, 2002). At this level, because different languages have different predicate-argument structures, grammaticalization patterns for sentential elements may differ across languages, and learners may activate their L1 grammaticalization patterns for the TL sentences (Talmy, 1985; Bock \& Levelt, 1994). This means that IL verbs may project the number of arguments as required and the thematic roles assigned to each of the arguments as their counterparts in the L1, resulting in L1 predicate-argument structure in IL grammatical construction. Because of their incomplete knowledge of certain TL lexical items, although learners may choose the right TL verbs, they may not know the predicate-argument structure as required by those verbs and use them inappropriately in IL production (cf. Wei, 2000a, 2000b). In other words, although learners produce the TL sentences, the grammar of these sentences is based on the predicate-argument structure of their L1. Consequently, transfer in predicate-argument structure may occur (Jake, 1998; Wei, 2002). The following are some of the typical instances produced by learners.

Example (6) densha o totte gakkoo ni iku. train PART/OBJ take school to go

'(I) take the train to go to school.'

In Example (6), the speaker uses the English predicate-argument structure for the verb toru/totte (take) where the means of transportation densha (train) is introduced as the THEME (the direct object). In Japanese, however, densha must be introduced as the LOCATIVE in a prepositional phrase, rather than introduced as the 
THEME, by the verb noru/notte. According to the Japanese predicate-argument structure, the same concept should be realized as below.

densha ni note gakkō ni iku.

trainin take school to go

'(I) take the train to go to school.'

Example (7) maiasa watashi wa kare no inu sanposaseru.

every morning I PART/TOP his dog walk

'I walk his dog every morning.'

In Example (7), the speaker uses the Japanese verb sanposaseru (walk) as a transitive verb whose object is the THEME (or PATIENT). However, in Japanese, the direct object or the THEME (or PATIENT) in this case, must be introduced by the particle ' $o$ ', but the speaker uses the English structure for the same concept.

Example (8a) haha wa shopping iku.

mother PART/TOP shopping go

'(My) mother goes shopping.'

In Example (8), the speaker translates the English expression "go shopping" into Japanese, violating the Japanese predicate-argument structure for the verb $i k u$ (go). While in English "shopping" is introduced as the GOAL by the verb "go", in Japanese shoppingu (shopping) is introduced as the GOAL by the preposition $n i$.

Example (8b) haha wa shopping ni iku. mother PART/TOP shopping for go

'(My) mother goes shopping.'

Part of the reason for the speaker to use the English predicate-argument structure in the Japanese production is that because shopping is a borrowed word from English, the speaker may generalize the English predicate-argument structure into the target production.

Example (9a) gozenchü kare o yonda.

in the morning him PART/OBJ called

'(I) called him in the morning.'

In Example (9), the speaker employs the English predicate-argument structure for the verb "call" yobulyonda where the semantic features of communicate with by telephone are conflated in the verb "call". Thus, in English the object of "call" is actually the RECIPIENT. Unlike in English, in Japanese the RECIPIENT must be introduced by a preposition and the phone-call itself must be introduced as the object, the THEME, by a specific verb such as kakeru or suru.

Example (9b) gozenchū kare ni denwa o kaketa (or:denwa o shita).

in the morning him in phone PART/OBJ called phone PART/OBJ did

'(I) called him in the morning.'

It is apparent that the speaker transfers the English predicate-argument structure for the similar lexical item "call" into the Japanese production.

Example (10a) kare no uchi made noseru o ageta.

his home to ride PART/OBJ gave

'(I) gave him a ride home.'

In Example (10), the speaker translates the English expression "give a ride” into Japanese, violating the target predicate-argument structure. While in English "ride" noseru is introduced as the object, the THEME, by 
the verb "give" ageru, in Japanese the means of transportation must be introduced by a preposition as the INSTRUMENT rather than the THEME, as shown below.

Example (10b) kare no uchi made kuruma de okutte ageta.

his home to car by sending gave

'(I) gave him a ride home.' (Literally: I sent you to your home by car.)

The above instances of learners' Japanese production show transfer from English in the predicate-argument structure for certain TL verbs, that is, learners' L1 may contribute its predicate-argument structure to IL construction at the functional level. In other words, although learners produce the TL verbs, the selections of those verbs are based on their knowledge of L1.

\section{Language Transfer in Morphological Realization Patterns}

The last level of speech production is the positional level realization of higher levels of lexical structure, where surface devices for case, agreement, tense/aspect marking, word order, etc. are achieved. At this level, because different languages have different morphological realization patterns, learners may adopt their L1 surface devices in the TL production (Liu, 1999, 2001; Wei, 2000a, 2002). The following are some of the typical instances produced by learners.

Example (11) watashitachi wa shigoto ni iku mainichi.

We PART/TOP work to go everyday

'We go to work everyday.'

In Example (11), although the sentence basically keeps the Japanese verb final order, the adverbial of time mainichi (everyday) appears in the sentence final position, which is not allowed in Japanese.

Example (12) watashi wa mō kaki-owatta watashi no repōto.

I PART/TOP already finished my paper

'I already finished my paper.'

The sentence in Example (12) is produced in the typical English word order where the object follows the predicate verb. Although the learner's violation of the TL surface word order does not frequently occur, such instances of transfer in morphological realization patterns from the learner's native language may still exist, especially in the early stage of learning.

Example (13) kono hon wa takai arimasen.

this book PART/TOP expensive be not

'This book is not expensive.'

In Example (13), the adjective takai should be conjugated as takaku in the negative sentence, but the speaker simply negates the verb according to the English rule without also conjugating the adjective.

Example (14) sono hito wa yümei arimasen.

that person PART/TOP famous be not

'That person is not famous.'

In Example (14), the speaker negates the verb aru (be) according to the similar rule in English without including $j a$ in the predicate verb. The learner fails to recognize that in Japanese if the adjective belongs to the $n a$-adjective, in the negative predicate jaarimasen, $j a$ is part of the morphological pattern.

Example (15) watashi wa kono hon o yomu nai.

I PART/TOP this book PART/OBJ read not 
'I don't read this book.'

In Example (15), the speaker negates the verb according to the English rule without also changing the verb ending to yoma in the negative predicate.

Such instances of language transfer in morphological realization patterns reflect the fact that language-specific surface devices may also present learning difficulty especially to early stage learners, and such learning difficulty is partly caused by transfer from learners' L1.

\section{Conclusion}

Although it has been recognized in SLA studies that not all learner errors are caused by language transfer, potential language transfer or L1 influence in second or foreign language learning has become a commonly observed phenomenon. The IL performance instances discussed in this study provide the evidence that learners may apply their L1 strategies to L2 vocabulary acquisition, grammar construction, and sentence formulation. This study explores the sources of language transfer at three levels of speech production. At the conceptual level, language transfer may occur in lexical-conceptual structure, where learners may activate and select TL lexical items based on similar lexical items in their L1. In other words, learners' intended meanings are translated into the TL by using their L1 lexical-conceptual structure. At the functional level, language transfer may occur in predicate-argument structure, where learners may adopt their L1 grammaticalization patterns in constructing TL sentences. In other words, if such a transfer occurs, TL sentences will be constructed based on L1 syntactic rules. At the positional level, language transfer may occur in morphological realization patterns, where learners may violate TL morphological requirements by using their L1 morphological realization patterns for morphology and surface word order. In other words, learners may adopt their L1 surface devices in the TL production.

This study concludes that learners' incomplete knowledge of the TL specifically includes their incomplete knowledge of TL abstract lexical structure, including lexical-conceptual structure at the conceptual level, predicate-argument structure at the functional level, and morphological realization patterns at the positional level. Language transfer may occur at any of the three levels of speech production during second or foreign language learning. Thus, language transfer is viewed as part of the learning process, rather than the surface products themselves. Since lexical-conceptual structure, predicate-argument structure, and morphological realization patterns are language-specific, they must be learned as such (Kellerman, 1984; Ellis, 1985; Gass \& Selinker, 2001; Wei, 2002). Sufficient acquisition of the TL abstract lexical structure will eventually replace the previously learned ones in learners' L1.

\section{References}

Arabski, J. (1979). Errors as indications of the development of interlanguage. Katowice: UniwersytetSlaski.

Bailey, N., Madden, C., \& Krashen, S. D. (1974). Is there a "natural sequence" in adult second language learning? Language Learning, 24, 235-244.

Bierwisch, M., \& Schreuder, R. (1992). From concepts to lexical items. Cognition, 41, 23-60.

Bock, K., \& Levelt, W. J. M. (1994). Language production: Grammatical encoding. In M. A. Gernsbacher (Ed.), Handbook of psycholinguistics (pp. 945-984). New York: Academic Press.

Corder, S. P. (1967). The significance of learners' errors. International Review of Applied Linguistics, 5, 161-170.

Corder, S. P. (1981). Error analysis and interlanguage. Oxford: Oxford University Press.

De Bot, K., \& Schreuder, R. (1993). Word production and the bilingual lexicon. In R. Schreuder \& B. Weltens (Eds.), The bilingual lexicon (pp. 191-214). Amsterdam, The Netherlands: John Benjamins. 
Dulay, H. C., Burt, M. K., \& Krashen, S. D. (1982). Language two. New York: Oxford University Press.

Ellis, R. (1982). The origins of interlanguage. Applied Linguistics, 3, 207-223.

Ellis, R. (1985). Understanding second language acquisition. Oxford, United Kingdom: Oxford University Press.

Færch, C. \& Kasper, G. (Eds.). (1987). Introspection in second language research. Clevedon: Multilingual Matters.

Færch, C., \& Kasper, G. (1986). Cognitive dimensions of language transfer. In E. Kelleerman \& M. Sharwood Smith (Eds.), Cross-linguistic influence in second language acquisition (pp. 49-65). Elmsford, NY: Pergamon Press.

Gass, S. M. (1996). Transference and interference. In H. Goebl, P. H. Nelde, Z. Starý, \& W. Wölck (Eds.), Contact linguistics: An international handbook of contemporary research (Vol. 1, pp. 558-567). Berlin: Waler de Gryuter.

Gass, S. M., \& Selinker, L. (2001). Second language acquisition. An introduction. Mahwah, NJ: Lawrence Erlbaum Associates, Publishers.

Gass, S. M., \& Selinker, L. (Eds.). (1992). Language transfer in language learning. Amsterdam: John Benjamins.

Jackendoff, R. (1990). Semantic structures. Cambridge, MA: MIT Press.

Jake, J. L. (1998). Constructing interlanguage: Building a composite matrix language. Linguistics, 36, 334-377.

Kellerman, E. (1984). The empirical evidence for the influence of the LI in interlanguage. In A. Davies, C. Griper, \& A. P. R. Howatt (Eds.), Interlanguage (pp. 98-122). Edinburgh, U.K.: Edinburgh University Press.

Kellerman, E., \& Sharwood Smith, M. (Eds.). (1986). Cross-linguistic influence in second language acquisition. Elmsford, NY: Pergamon Press.

Kroll, J. F., \& De Groot, A. M. B. (1997). Lexical and conceptual memory in the bilingual: Mapping form to meaning in two languages. In A. M. D. De Groot \& J. F. Kroll (Eds.), Tutorials in bilingualism, psycholinguistic perspectives (pp. 169-199). Mahwah, NJ: Lawrence Erlbaum Associates, Publishers.

Lado, R. (1957). Linguistics across cultures: Applied linguistics for language teachers. Ann Arbor, MI: University of Michigan Press.

Levelt, W. J. M. (1989). Speaking: From intention to articulation. Cambridge, MA: MIT Press.

Levin, B., \& Pinker, S. (1991). Introduction to the special issue of cognition on lexical and conceptual semantics. Cognition, 41, $1-7$.

Liu, X. (1999). The Japanese verb conjugation system: Learning difficulties and teaching methods. In The Proceedings of the 14th Annual Conference of Southeastern Association of Teachers of Japanese. Retrieved from http:/seatj.org/proceedings/

Liu, X. (2001).The integration of language form and function as a teaching principle. In The Proceedings of the 16th Annual Conference of the Southeastern Association of Teachers of Japanese. Retrieved from http://seatj.org/proceedings/

Myers-Scotton, C. (1994). Language processing and the mental lexicon in bilinguals. In R. Dirven \& J. Vanparys (Eds.), New approaches to the lexicon (pp. 73-100). Frankfurt: Peter Lang.

Myers-Scotton, C., \& Jake, J. L. (1995). Matching lemmas in a bilingual language competence and production model: Evidence from intrasentential code switching. Linguistics, 33(5), 991-1024.

Odlin, T. (1989). Language transfer. Cambridge: Cambridge University Press.

Pinker, S. (1989). Learnability and cognition. Cambridge, MA: MIT Press.

Rappaport, M., \& Levin, B. (1988). What to do with theta-roles. In W. Wilkins (Ed.), Syntax and Semantics: Vol. 21. Thematic relations (pp. 7-34). New York: Academic Press.

Ringbom, H. (1987). The role of the first language in foreign language learning. Clevedon, Avon: Multilingual Matters.

Schachter, J. (1983). A new account of language transfer. In S. Gass \& L. Selinker (Eds.), Language transfer in language learning (pp. 98-111). Rowley, MA: Newbury House Publishers.

Talmy, L. (1985). Lexicalization patterns: Semantic structure in lexical forms. In T. Shopen (Ed.), Language Typology and Syntactic Description: Vol. 3. Grammatical categories and the lexicon (pp. 57-138). Cambridge: Cambridge University Press.

Wei, L. (2000a). Unequal election of morphemes in adult second language acquisition. Applied Linguistics, 21(1), 106-140.

Wei, L. (2000b). Types of morphemes and their implications for second language morpheme acquisition. International Journal of Bilingualism, 4(1), 29-43.

Wei, L. (2002). The bilingual mental lexicon and speech production process. Brain and Language, 81, 691-707. 